\title{
Practices and Results of Two Years Service from a Single UK Renal Transplant Center
}

\author{
Shrestha PC, ${ }^{1}$ Dominguez-Escrig J, ${ }^{1}$ Gowardhan B, ${ }^{1}$ Rix D, ${ }^{1}$ Talbot D \\ 'Department of Transplant Surgery, Freeman Hospital, Newcastle upon Tyne, UK.
}

\section{ABSTRACT}

Introduction: End stage renal failure is a common condition requiring renal replacement therapy in the form of haemodialysis or peritoneal dialysis as a short-term measure with renal transplantation as a more definitive treatment option. The aim of this study was to evaluate the set up of a renal transplant unit in a developed country and compare its results with other centers of the world.

Methods: A retrospective observational study was conducted to see the results of two years activities of a well known renal transplant unit in the United Kingdom. A description of the setup of a renal transplant unit has been made and its results have been discussed.

Results: Of the total patients, who had transplants in the renal transplant unit in year 2006 and 2007, 209 were renal, 14 were simultaneous kidney pancreas and two were pancreas after kidney transplants. Our one year graft survival rate was 93\%, delayed graft function was 15\%, early rejection rate was $11 \%$ and mortality rate was $3 \%$ in one year follow up.

Conclusions: To attain good results in renal transplantation surgery, a multi-disciplinary team approach is crucial. Our set up is an example where the results are comparable to published and unpublished data from other established units world-wide.

Key Words: complications, immunosuppression, renal transplant

\section{INTRODUCTION}

End Stage Renal Failure is a common problem encountered in developed as well as developing countries around the world. The Nephrologists conventionally manage this by renal replacement therapy in the form of haemodialysis or peritoneal dialysis. Over the last 50 years, the role of renal transplant has become the mainstay of management of these patients. This has become safer with the introduction of an array of immunosuppressive drugs to

\author{
Correspondence: \\ Dr. Pukar Chandra Shrestha \\ Department of Transplant Surgery \\ Freeman Hospital, High Heaton \\ Newcastle upon Tyne, NE7 7DN, UK. \\ Email: pukar@doctors.org.uk \\ Phone: 00441912137128
}


help with the prevention and management of rejection as a result of tissue mismatch. Graft survival has improved and with experience the complication rates have reduced. ${ }^{1}$

Here we present a description of the layout and functioning of our department along with the protocols adopted in our unit for immunosuppression, which are unique to our center. We also present the results of two years (2006 and 2007) with discussion of complications.

\section{METHODS}

A retrospective study was conducted on transplantations performed in renal transplantation unit, Freeman Hospital, High Heaton Newcastle upon Tyne, UK from January, 2006 - December, 2007. After institutional approval, data on all the transplantation were collected from hospital records. Primary disease pattern, type of transplantations and post operative complications were evaluated. Statistical analysis was done by using statistical package for social sciences (SPSS) version 16 for windows.

\section{RESULTS}

The renal transplant unit in Newcastle carried out 225 transplants in the years 2006 and 2007 (Table 1, Figure 1). Of the total, 209 were renal, 14 were simultaneous kidney pancreas (SKP) and two were pancreas after kidney (PAK) transplants. Of the renal transplants alone, 206 were adult and 17 were paediatric renal transplants. The mean age of renal transplant recipients was 44 years (range 4 to 77 years). Male to Female ratio was 1.6:1.

As per the unit immunosuppression policy, all the Live and Cadaver donor transplant patients (160) received Basiliximab, all NHBD transplant patients (63) received Daclizumab. Tacrolimus was given in 220 patients and three patients received Cyclosporine. Rituximab was given to two patients previously sensitized with pre formed antibodies.

With up to one year follow up, 93\% transplant grafts are functioning. 15\% patients had Delayed Graft Function (DGF) needing more than one session of dialysis after transplant. $11 \%$ patients had early rejection requiring treatment with high dose pulsed Methylprednisolone.

Complications were comparable to data from other regional centers within UK (Table 2). A total of 62 biopsies of the transplant kidney were done for impaired graft function (Table 3,4).

Out of the 62 patients having biopsies of the transplant kidney, 14 patients were treated with high dose pulsed Methylprednisolone alone, seven required Anti Thymocyte globulin (ATG) for vascular rejection, three had ATG and
Plasma Exchange (PE) and Steroid combined treatment. Three patients received intravenous Immunoglobulin and one had an urgent parathyroidectomy. No action was taken in 34 patients. Fifteen patients needed repeat biopsies. Of these, five had acute cellular rejection, seven had acute tubular necrosis (reports were not accessible in three patients). Two needed ATG + FFP + PE combined treatment, three had high dose pulsed Methylprednisolone. Seven were managed without any medical intervention but data could not be accessed on three patients.

In all, 26 patients needed secondary surgical interventions. Seven patients needed nephrostomy / stenting because of hydronephrosis. Three had marsupialisation of lymphocele (though one failed as the collection was too small). Two had laparotomy for intestinal obstruction and one needed pancolectomy for uncontrolled $C$. difficille diarrhoea/peritonitis. Three required drainage of an intraabdominal abscess. Four had laparotomy for bleeding and one patient needed exploration of transplant kidney site for seven times for the difficult bleeding diagnosed angiographically as a leak from the arterial anastomotic site. Four patients had graft nephrectomy - two for venous thromobosis, one for bleeding from the internal iliac vein and one due to thrombo-angiopathy secondary to recurrence of native disease. A single pancreas transplant (after a previous kidney transplant) failed due to graft thrombosis and needed removal.

In all seven patients who died - five were renal transplant recipients and two were SKP recipients (Simultaneous Kidney Pancreas transplant). Of the five renal recipients, one died of sepsis and Cerebro Vascular Accident; one from Post Transplant Lympho Proliferative Disease (PTLD) with bleeding and sepsis; another one from small bowel perforation and sepsis, one died due to pulmonary embolism. However one renal transplant recipient who died after sudden headache and seizure had an inconclusive post-mortem examination. One of the patients with SKP transplant died following bleeding from arterial anastomosis site secondary to fungal infection and another SKP recipient died because of spinal cord ischaemia, tracheomalacia and sepsis.

\section{DISCUSSION}

Delayed graft function accounted $15 \%$ in our series which is comparable to other studies showing $10-50 \%$. Overall rejection rate in renal transplant has been reported to be around $20 \%$ whereas it was $11.5 \%$ in our study. ${ }^{2}$

Our one year graft survival rate was $93 \%$ which is consistent with other study results. ${ }^{1,3-7}$ Mortality rate in our centre during the study period was $3 \%$ which is less than the data in other international publications which have reported $5 \% .^{2}$ 
Renal vascular thrombosis rate was $1 \%$ in our centre which is consistent with the range from 0.5 to $8 \%$ as reported by other different studies. Other surgical complications in early post transplant days included bleeding, wound infection, lymphocele and haematoma and urinary leak from ureterovesico anastomosis site which are also comparable with other series. ${ }^{1,28-12}$ Likewise, the incidence of medical complications is also fairly comparable with other results from different studies.

\section{CONCLUSIONS}

To attain good results in renal transplantation surgery, a multi-disciplinary team approach is crucial. The results are comparable to other published and unpublished data as are the complications.

Table 1. Demographics of transplants in Renal Transplant unit for the year 2006 and 2007

\begin{tabular}{ll}
\hline Transplant Procedure & Number \\
\hline Adult Kidney Transplants & 206 \\
Paediatric Kidney Transplants & 17 \\
Simultaneous Kidney Pancreas & 14 \\
Transplants (SKP) & 2 \\
Pancreas after Kidney (PAK) & \\
\hline
\end{tabular}

Table 2. Distribution of post transplant medical and surgical complications

\begin{tabular}{|c|c|c|c|}
\hline \multicolumn{3}{|c|}{ Complications } & \multirow{2}{*}{$\frac{\text { Number of cases }(\%)}{16(7.1 \%)}$} \\
\hline Medical complications & Infections & UTI & \\
\hline & & Chest infection & $7(3.1 \%)$ \\
\hline & & C. difficile diarrhea & $6(2.7 \%)$ \\
\hline & & Septicaemia & $1(0.5 \%)$ \\
\hline & Cardiovascular & MI & $4(1.7 \%)$ \\
\hline & & $\mathrm{AF}$ & $4(1.7 \%)$ \\
\hline & & Hypotension & $3(1.3 \%)$ \\
\hline & Post transplant diabetes & $6(2.9 \%)$ & \\
\hline & Upper GI bleed & & $4(1.2 \%)$ \\
\hline & Skin rash & & $1(0.5 \%)$ \\
\hline & Deranged LFT & & $1(0.5 \%)$ \\
\hline \multirow[t]{8}{*}{ Surgical Complications } & Collection / Abscess & & $11(4.8 \%)$ \\
\hline & Wound related & Infections / dehiscence & $13(5.8 \%)$ \\
\hline & & Haematoma & $5(2.2 \%)$ \\
\hline & Urine leak & & $5(2.2 \%)$ \\
\hline & Peritonitis & & $2(1 \%)$ \\
\hline & Small bowel obstruction & & $1(0.5 \%)$ \\
\hline & Intra-abdominal bleed & & $7(3.1 \%)$ \\
\hline & Pancreatic fistula & & $3(19 \%)$ \\
\hline
\end{tabular}

Table 3. Results of first transplant biopsies in posttransplant patients

\begin{tabular}{lcl}
\hline Biopsy result & Number of cases & $\%$ \\
\hline Acute Tubular Necrosis (ATN) & 26 & 12 \\
Acute Cellular Rejection (ACR) & 13 & 6 \\
Acute Vascular Rejection (AVR) & 8 & 4 \\
Antibody Mediated Rejection & 3 & 1.5 \\
Infarction & 2 & 1 \\
Calcinosis & 1 & 0.5 \\
Polyoma virus infection & 1 & 0.5 \\
Normal & 8 & 4 \\
\hline
\end{tabular}

Table 4. Removal of Grafts and Mortality

\begin{tabular}{lcccc}
\hline & Yr 2006 & Yr 2007 & Total & $\%$ \\
\hline Transplant Nephrectomy & 1 & 3 & $4 / 223$ & 1.7 \\
Graft Pancreatectomy & 0 & 1 & $1 / 16$ & 6 \\
Post Transplant mortality & 4 & 3 & $7 / 225$ & 3 \\
Live donor mortality & 0 & 0 & 0 & 0 \\
\hline
\end{tabular}




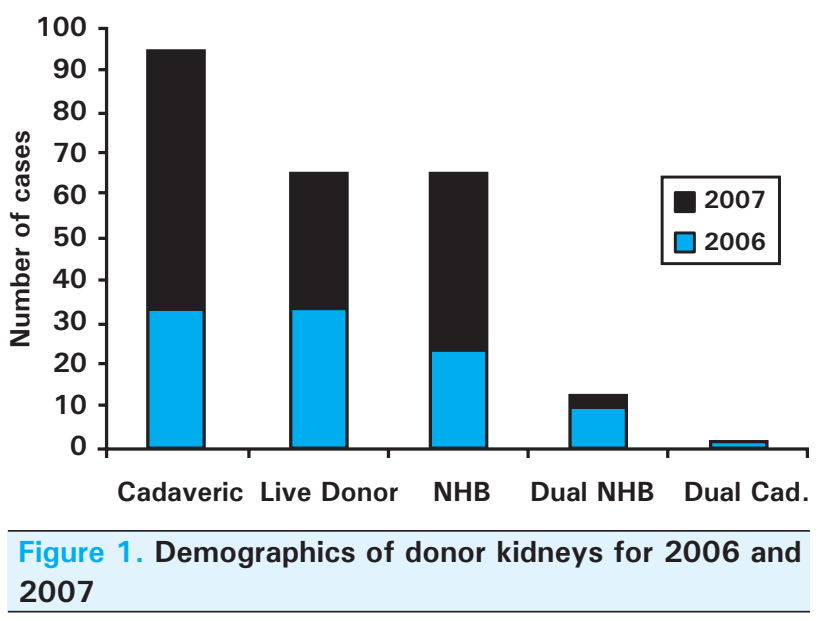

Freeman Hospital All UK centres

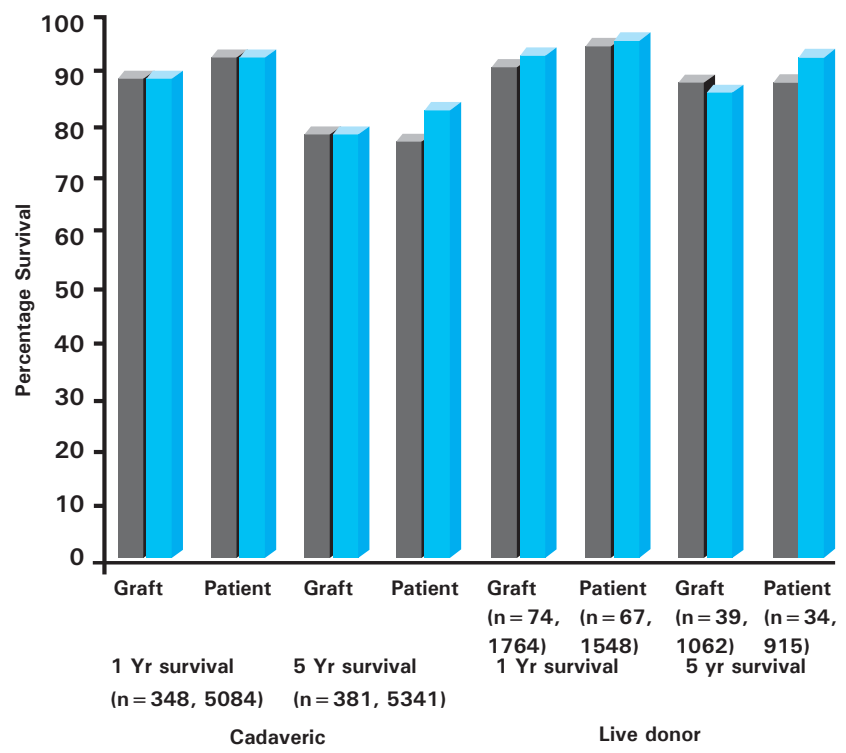

Figure 2. Graphical representation of percentage survival of both grafts and patients in the cadaveric and live donor groups comparing Freeman hospital with all UK centres. Numbers in bracket are for Freeeman hospital and all UK centres respectively

\section{REFERENCES}

1. Kalble T, Lucan M, Nicita G, Sells R, Burgos Revilla FJ, Wiesel M. EAU Guidelines on Renal Transplantation. Eur Urol. 2005;47(2):156-66.

2. Danovitch GM. Handbook of kidney transplantation. 4th ed. Philadelphia: Lippincott Williams \& Wilkins; 2005.

3. Cecka JM. The UNOS Scientific Renal Transplant Registry. Clin Transpl. 1998:1-16.

4. Opelz G. Collaborative Transplant study- 10-year report. Transplant Proc. 1992;24:2342-55.

5. Opelz G. Impact of HLA compatibility on survival of kidney transplants from unrelated live donors. Transplantation. 1997;64:1473-5.

6. Terasaki PI, Cecka JM, Gjertson DW, Takemoto S. High survival rates of kidney transplants from spousal and living unrelated donors. New Eng J Med. 1995;333:333-6.

7. Terasaki PI. The HLA-matching effect in different cohorts of kidney transplant recipients. Clin Transpl. 2000;497-514.
8. Humar A, Rancharan T, Denny R, Gullingham KJ, Payne WD, Mtas AJ. Are wound infections after kidney transplant more common with modern immunosupression? Transplantation. 2001;72:1920-3

9. Hriko GM, Birtch AG, Bennet AH, Wilson RE. Factors responsible of urinary fistula in the renal transplant recipient. Ann Surg. 1973;178:609-15.

10. Prompt CA, Manfro RC, Ilha De O, Koff KJ. Caliceal-cutanous fistula in renal transplantation: successful conservative management. J Urol. 1990;143:580-1.

11. Kinnaert P, Hall M, Janseen F, Vereestraeten P, Toussaint G, Van Geertruyden J. Ureteral stenosis after kidney transplantation: true incidence and long-term followup after surgical correction. J Urol. 1985;133:17-20.

12. Salvatierra O Jr, Olcott C 4th, Amend WJ Jr, Cochrum KC, Freduska NJ. Urological complications of renal transplantation can be prevented or controlled. J Urol. 1977 Apr;117(4):421-4. 